\title{
Antioxidant capacity, polyphenol content and iron bioavailability from algae (Ulva sp., Sargassum sp. and Porphyra sp.) in human subjects
}

\author{
Maria N. García-Casal*, José Ramírez, Irene Leets, Ana C. Pereira and Maria F. Quiroga \\ Laboratorio de Fisiopatología, Instituto Venezolano de Investigaciones Científicas (IVIC), Carretera Panamericana, Centro \\ de Medicina Experimental, Apartado 21827, Caracas 1020-A, Venezuela
}

(Received 6 December 2007 - Revised 28 February 2008 - Accepted 31 March 2008 - First published online 18 July 2008)

Marine algae are easily produced and are good sources of Fe. If this Fe is bioavailable, algae consumption could help to combat Fe deficiency and anaemia worldwide. The objective of the present study was to evaluate Fe bioavailability, polyphenol content and antioxidant capacity from three species of marine algae distributed worldwide. A total of eighty-three subjects received maize- or wheat-based meals containing marine algae (Ulva sp., Sargassum sp. and Porphyra sp.) in different proportions (2.5, 5.0 and 7.5 g) added to the water to prepare the dough. All meals administered contained radioactive Fe. Absorption was evaluated calculating radioactive Fe incorporation in subjects' blood. The three species of marine algae were analysed for polyphenol content and reducing power. Algae significantly increased Fe absorption in maize- or wheat-based meals, especially Sargassum sp., due to its high Fe content. Increases in absorption were dose-dependent and higher in wheat- than in maizebased meals. Total polyphenol content was 10.84, 18.43 and 80.39 gallic acid equivalents/g for Ulva sp., Porphyra sp. and Sargassum sp., respectively. The antioxidant capacity was also significantly higher in Sargassum sp. compared with the other two species analysed. Ulva sp., Sargassum sp. and Porphyra sp. are good sources of bioavailable Fe. Sargassum sp. resulted in the highest Fe intake due to its high Fe content, and a bread containing 7.5 g Sargassum sp. covers daily Fe needs. The high polyphenol content found in Sargassum sp. could be partly responsible for the antioxidant power reported here, and apparently did not affect Fe absorption.

Iron bioavailability: Polyphenols: Antioxidant capacity: Maize: Wheat: Algae

The use of algae for human consumption has been documented for hundreds of years in some cultures ${ }^{(1)}$. More recently, and due to globalisation, patterns of consumption have changed around the world. For example, the adaptation of macrobiotic diets adopted from Japan by European countries produced the inclusion of marine vegetables in their diets. In 2003, it was estimated that about 1 million tons of algae were harvested in thirty-five countries as food, fuel and cosmetic sources ${ }^{(2)}$.

In contrast, there are other tropical countries with a vast variety of algae species, with high growing rates, sometimes constituting a problem for ecological and tourism development, where algae consumption is not a regular practice. Paradoxically, in these geographical zones there are important nutritional and economic deficiencies, that the use of their own produced algae could help to ameliorate. The extraordinary nutritional composition of algae in terms of fibre, protein, minerals and vitamins, as well as their low-fat and non-digestible carbohydrate content, make algae a nutritive, low-energy food which represents an important food alternative ${ }^{(3-7)}$.

Algae are also being studied as a source of antioxidants ${ }^{(3,8)}$ Epidemiological data obtained in rodents showed the protective effect of red and green algae against intestinal, skin and breast cancer ${ }^{(9)}$. One mechanism proposed to explain inhibition in carcinogenesis was mediated by an algae component that increased antioxidant enzyme activity and reduced lipid oxidation in the rat liver ${ }^{(10)}$.
In spite of the intense investigative effort and the recent knowledge generated in $\mathrm{Fe}$ metabolism, anaemia and $\mathrm{Fe}$ deficiency constitute important nutritional deficiencies worldwide $^{(11)}$. The most common approaches to combat these deficiencies are $\mathrm{Fe}$ supplementation and food fortification which require a highly available source of Fe. Nutritional education and diet changes to include foods with a high content of bioavailable $\mathrm{Fe}$ are also important approaches ${ }^{(12,13)}$.

The search for alternative, bioavailable and inexpensive sources of food $\mathrm{Fe}$ is desirable, especially in underdeveloped countries. Algae could be interesting candidates to explore as $\mathrm{Fe}$ sources, especially in countries where algae production is feasible. Since Fe bioavailability from algae has not been extensively studied, and due to the relationship between $\mathrm{Fe}$ bioavailability and polyphenol content in foods, as well as the role of these two nutrients in the generation and metabolism of antioxidants, the objective of the present work was to study Fe bioavailability, polyphenol content and antioxidant capacity from three species of marine algae (Ulva sp., Sargassum sp. and Porphyra sp.) distributed worldwide.

\section{Materials and methods \\ Selection of algae for human consumption}

Algae were collected by swimming and diving from four beaches in Margarita Island, Venezuela by trained personnel of 
Biotecmar CA. Material collected was classified and washed with sea water eliminating impurities such as sand, rocks, epiphytes and epifauna. Algae were sun-dried for $6 \mathrm{~h}$ and for further $12 \mathrm{~h}$ in the shade before they were packed, labelled and refrigerated at $4{ }^{\circ} \mathrm{C}$ until transported to the laboratory.

After an initial screening for Fe content, three algae were selected for Fe bioavailability studies with maize and wheat breads. These species (Ulva sp., Sargassum sp. and Porphyra sp.) were washed by immersion in tap water for five times, followed by soaking for $30 \mathrm{~min}$ with a water change at $15 \mathrm{~min}$. To eliminate excess of water, samples were placed on paper towels for $1 \mathrm{~h}$ and freeze dried to constant weight. Dried samples were used for total polyphenol content, reducing power and $\mathrm{Fe}$ bioavailability studies.

\section{Total polyphenol content}

Total phenolic compounds were determined by the Folin-Ciocalteu method $^{(14)}$. A sample of $200 \mu \mathrm{l}$ was added to $1 \mathrm{ml} \mathrm{1:10}$ diluted Folin-Ciocalteu reagent. After incubation for $4 \mathrm{~min}$, $800 \mu \mathrm{l}$ of sodium carbonate $(75 \mathrm{~g} / \mathrm{l})$ were added. Samples were incubated for $2 \mathrm{~h}$ at room temperature and absorbance measured at $750 \mathrm{~nm}$. A standard curve was prepared with gallic acid $(0-5 \mu \mathrm{g} / \mathrm{ml})$ and results were reported as gallic acid equivalents/g sample. Algae samples were prepared by extracting $1 \mathrm{~g}$ samples with $5 \mathrm{ml} 0 \cdot 1 \mathrm{M}-\mathrm{HCl}$ for $1 \mathrm{~h}$.

\section{Antioxidant capacity in algae}

Antioxidant capacity in algae was measured by the 'ferricreducing activity in plasma' (FRAP) method, reported by Benzie \& Strain in $1996^{(15)}$. Tripyridyltriazine reacts with ferric Fe to form a complex, which at low $\mathrm{pH}$ is reduced to ferrous $\mathrm{Fe}$ generating an intense blue colour absorbing at $593 \mathrm{~nm}$. Briefly, $750 \mu \mathrm{l}$ FRAP reagent containing tripyridyltriazine and ferric $\mathrm{Fe}$ in acetate buffer reacted with $25 \mu \mathrm{l}$ of sample. The absorbance was registered immediately at $593 \mathrm{~nm}$, and also after $4 \mathrm{~min}$ incubation. A standard curve was prepared with ferrous sulfate $(100-200 \mu \mathrm{M})$ and results were reported as $\mu \mathrm{mol} \mathrm{Fe} / 100 \mathrm{~g}$ dry algae. Algae samples were prepared by extracting $2 \mathrm{~g}$ samples with $5 \mathrm{ml} 0.1 \mathrm{M}$ $\mathrm{HCl}$ for $24 \mathrm{~h}$.

\section{Meal preparation}

Six absorption studies were performed using three species of algae, administered with maize or wheat breads. In each absorption study each subject received four meals. In meal 1, bread was prepared without algae addition and meals $2-4$ contained increasing amounts of algae. The first three studies were performed with Ulva sp., Sargassum sp. and Porphyra sp. administered with maize bread and the other three studies included the same algae administered with wheat bread.

All studies included a $110 \mathrm{~g}$ maize bread (prepared from $50 \mathrm{~g}$ non-enriched maize flour donated by Alimentos Polar Comercial, PROMESA, Venezuela) or a $100 \mathrm{~g}$ wheat bread (prepared from $50 \mathrm{~g}$ non-enriched wheat flour donated by Cargill de Venezuela), with $25 \mathrm{~g}$ cheese, $5 \mathrm{~g}$ margarine and a glass of water. Radioactive tagging $\left({ }^{59} \mathrm{Fe}\right.$ or $\left.{ }^{55} \mathrm{Fe}\right)$ was added to the water used to prepare the dough. In all studies, three different concentrations of each alga (Ulva sp., Sargassum sp. and Porphyra sp.) were administered to the same subject. In one study, the same subject received the basal meal without algae and $2.5,5.0$ or $7.5 \mathrm{~g}$ of each alga/bread in the other three meals. In studies 1 and 4, the alga studied was Ulva sp., in studies 2 and 5 Sargassum sp. and in studies 3 and 6, Porphyra sp. The amounts of algae included ranged 2.5$7.5 \mathrm{~g}$ algae/maize or wheat bread, since in preliminary experiments it was determined that the acceptance of the breads diminished when higher amounts of algae were included.

For maize experiments (studies 1-3):

Meal 1. Radioactive maize breakfast alone.

Meal 2. Radioactive maize breakfast with $2.5 \mathrm{~g}$ Ulva sp., Sargassum sp. or Porphyra sp.

Meal 3. Radioactive maize breakfast with $5.0 \mathrm{~g}$ Ulva sp., Sargassum sp. or Porphyra sp.

Meal 4. Radioactive maize breakfast with $7.5 \mathrm{~g}$ Ulva sp., Sargassum sp. or Porphyra sp.

Studies 4-6 were similar to studies 1-3 except that the basal breakfast consisted of wheat bread instead of maize bread.

\section{Iron bioavailability studies}

$\mathrm{Fe}$ absorption studies were performed in eighty-three adult volunteers (twenty-one men and sixty-two women) apparently in good health, although some of them presented mild to moderate Fe deficiency and/or anaemia. The subjects studied included males over 15 years of age, menopausal and childbearing-age women. To the last group, a pregnancy test was performed. Each subject received four meals in each study and was allowed to participate in only one study. On day 1 of the experiment, pregnancy tests were performed and selected individuals were informed about the objectives and procedures of the study. A written consent form was signed by each volunteer. The study was approved by the Ethical Committee of the Venezuelan Institute for Scientific Research.

Meal 1, tagged with ${ }^{59} \mathrm{Fe}(0.0333 \mathrm{MBq}(0.9 \mu \mathrm{Ci})$ per individual), was administered to the subjects after an overnight fast. Meal 2, also extrinsically labelled, but with ${ }^{55} \mathrm{Fe}(0.0481 \mathrm{MBq}(1.3 \mu \mathrm{Ci})$ per individual), was fed $4 \mathrm{~h}$ later. No food or drink (except for water) was allowed between meals 1 and 2 , and $4 \mathrm{~h}$ after administration of meal 2. The protocol for the administration of radioactive food in the morning after an overnight fast and the afternoon of the same day was based on experiments previously published ${ }^{(16)}$.

On day 15 , blood $(30 \mathrm{ml})$ was drawn to determine the haematological profile $\left(\mathrm{Hb}\right.$ concentration ${ }^{(17)}$, serum $\mathrm{Fe}^{(18)}$, unsaturated binding capacity ${ }^{(19)}$ and serum ferritin concentration $^{(20)}$ ) and to measure radioactivity incorporation into erythrocytes. Duplicate $(10 \mathrm{ml})$ and triplicate samples of radioactive food were prepared for radioactive counting using the technique of Dern \& $\mathrm{Hart}^{(21,22)}$. Fe absorption from each meal was calculated from the radioactivity in the subject's blood using an estimate of blood volume based on sex, weight and height ${ }^{(23)}$.

On the same day (day 15), meals 3 and 4 were administered following the same protocol as for meals 1 and 2. On day 30, a blood sample was taken to measure radioactivity incorporation and serum ferritin concentration. 


\section{Statistical analysis}

Data analysis was based on comparisons (repeated-measures ANOVA with Bonferroni as a post-test) between absorption values for the four meals in each study. Mean values and standard deviations were calculated for all anthropometric and haematological measurements. Geometric values and standard errors were calculated for all absorption data and ferritin concentrations. The statistical analysis was performed using GraphPad InStat (GraphPad Software Inc., San Diego, CA, USA) and Excel (Microsoft Corporation, Redmond, WA, USA) programs.

\section{Results}

The total Fe content of non-enriched flours was $1.7 \mathrm{mg} / 100 \mathrm{~g}$ for maize flour and $2.4 \mathrm{mg} / 100 \mathrm{~g}$ for wheat flour. The mean Fe content of algae used in the bioavailability studies was 57.5 (SD 31.1) mg Fe/100 g dry weight for Ulva sp., 156.9 (SD 32.4) $\mathrm{mg} \mathrm{Fe} / 100 \mathrm{~g}$ dry weight for Sargassum sp. and 15.5 (SD 2.9) mg Fe/100 g dry weight for Porphyra sp. The algae were included in bread meals at $2.5,5.0$ and $7.5 \mathrm{~g}$ algae/bread. Accordingly, the Fe content of the maize meals administered ranged from 1.48 to $2.74 \mathrm{mg}$ Fe for Ulva sp., 2.72 to 6.46 for Sargassum sp. and 0.98 to 1.25 for Porphyra sp. For wheat-containing meals, Fe content fluctuated between 1.83 and $3.09 \mathrm{mg}$ Fe for Ulva sp., 3.07 and 6.81 for Sargassum sp. and 1.33 and 1.59 for Porphyra sp.

\section{Total polyphenol content}

As shown in Table 1, the total polyphenol content was higher in Sargassum sp. compared with the other two species tested. The difference in gallic acid equivalents was up to seven and three times greater for Sargassum sp. than for Ulva sp. or Porphyra sp., respectively.

\section{Antioxidant capacity in algae}

Antioxidant capacity expressed as $\mu \mathrm{mol} \mathrm{Fe} / 100 \mathrm{~g}$ dry algae showed that Sargassum sp. presented the highest reducing power, which was approximately double compared with

Table 1. Total polyphenol content and antioxidant power of acidic extracts from Ulva sp., Porphyra sp. and Sargassum sp. selected for human consumption*

(Mean values and standard deviations)

\begin{tabular}{|c|c|c|c|c|}
\hline \multirow[b]{2}{*}{ Algae } & \multicolumn{2}{|c|}{$\begin{array}{l}\text { Total polyphenols } \\
\text { (gallic acid equiva- } \\
\text { lents/g dry algae) }\end{array}$} & \multicolumn{2}{|c|}{$\begin{array}{c}\text { Antioxidant power } \\
(\mu \mathrm{mol} / 100 \mathrm{~g} \text { dry } \\
\text { algae }\end{array}$} \\
\hline & Mean & SD & Mean & SD \\
\hline Ulva sp. & $10 \cdot 84$ & $1 \cdot 28$ & 464 & 145 \\
\hline Porphyra sp. & $18 \cdot 43$ & $2 \cdot 17$ & 421 & 150 \\
\hline Sargassum sp. & $80 \cdot 39$ & $43 \cdot 8$ & 963 & 219 \\
\hline
\end{tabular}

* Selected algae was washed and hydrated by immersion in distilled water for $30 \mathrm{~min}$, as described in Materials and methods. Excess of water was eliminated by extending algae on absorbent paper for $1 \mathrm{~h}$, and freeze-dried to constant weight. Extraction was performed with $0.1 \mathrm{M}-\mathrm{HCl}$ for $1 \mathrm{~h}$ at room temperature. Extracts were filtered and polyphenols were determined by the method of Singleton \& Rossi ${ }^{(14)}$. For the 'ferric-reducing activity in plasma' (FRAP) assay, algae were extracted in acid for $24 \mathrm{~h}(n 4-12)$.
Ulva sp. or Porphyra sp., with similar antioxidant capabilities (Table 1).

\section{Meal preparation}

The appearance of maize and wheat breads prepared with $2 \cdot 5$, 5.0 and $7.5 \mathrm{~g}$ of Sargassum sp., Ulva sp. and Porphyra sp. is shown in Figs. 1 and 2. In spite of the change in appearance as the algae content was increased, there was no problem for the subjects participating in the studies to accept and consume these products, coming back on two other occasions to finish the study.

\section{Iron bioavailability studies}

The anthropometrical and haematological characteristics of the subjects participating in all the absorption studies that were performed are presented in Table 2.

Anthropometrical parameters were similar for all groups studied, including the higher number of female over male participants. Fe metabolism parameters were also similar among groups. $\mathrm{Hb}$ concentrations were comparable between groups and none of them could be classified as anaemic or Fedeficient groups based on mean $\mathrm{Hb}$ and ferritin concentrations, respectively. However, when analysed subject by subject, in groups 1-6 it was found that five, zero, five, four, three and three individuals were anaemic, respectively.

Fe bioavailability from maize bread containing different concentrations of algae $(2.5,5.0$ and $7.5 \mathrm{~g}$ algae/maize bread) significantly increased $\mathrm{Fe}$ absorption compared with the maize bread given alone. In Table 3, it can also be noticed that the addition of any of the three species analysed (Ulva sp.,
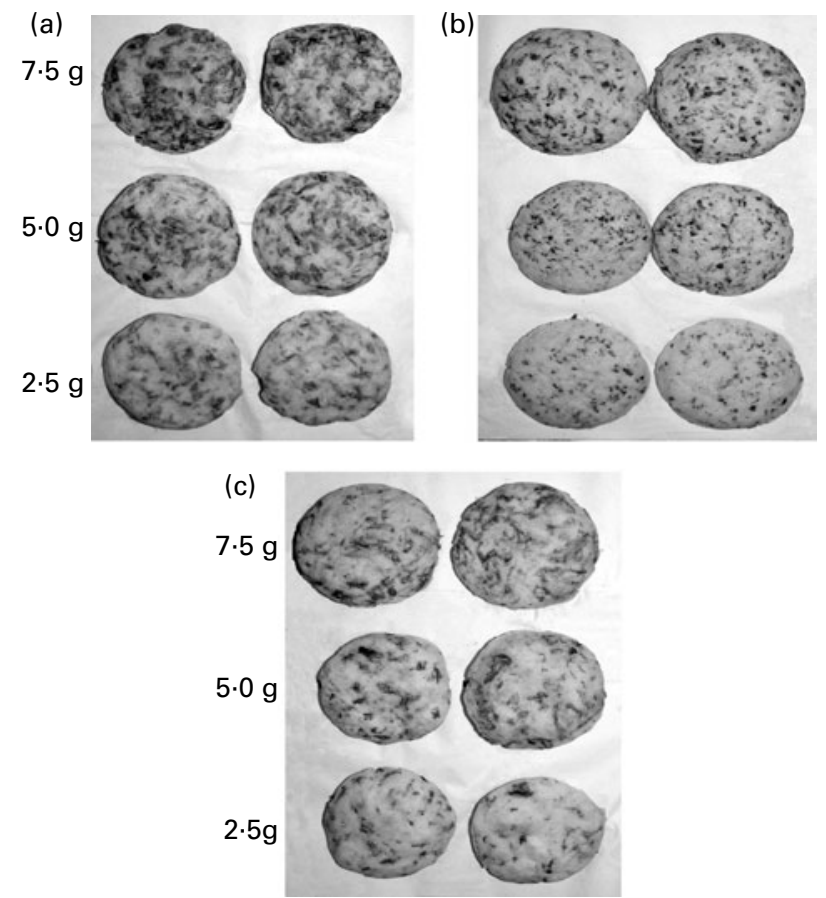

Fig. 1. Maize bread (arepa) prepared with $2.5,5.0$ and $7.5 \mathrm{~g}$ of (a) Ulva sp., (b) Sargassum sp. and (c) Porphyra sp. selected for human consumption and $\mathrm{Fe}$ bioavailability experiments. 
(a)

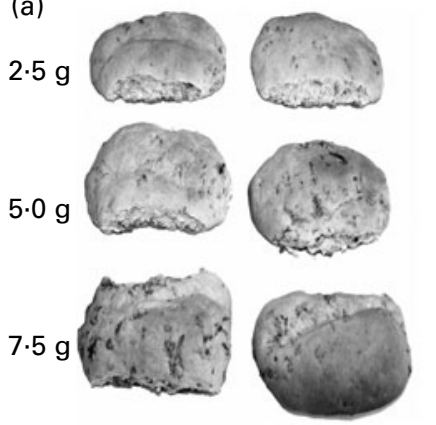

(b)
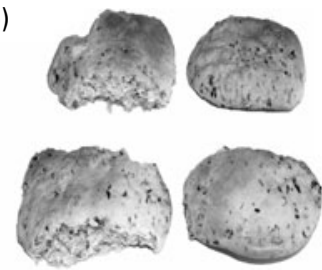

(c)
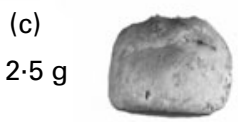

$5.0 \mathrm{~g}$
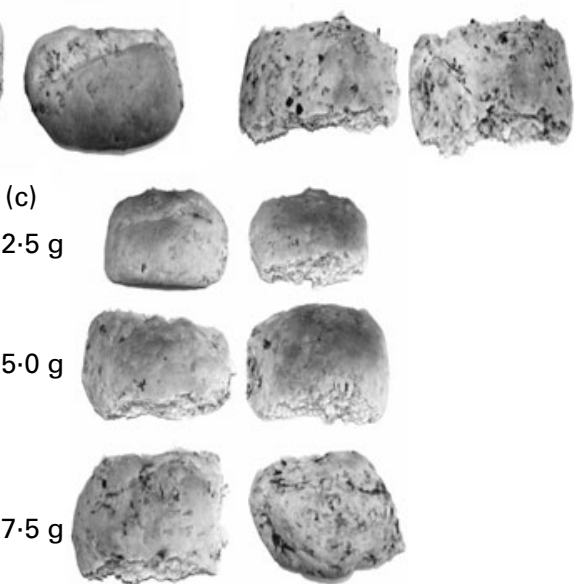

Fig. 2. Wheat bread prepared with $2.5,5.0$ and $7.5 \mathrm{~g}$ of (a) Ulva sp., (b) Sargassum sp. and (c) Porphyra sp. selected for human consumption and Fe bioavailability experiments.

Sargassum sp. or Porphyra sp.) was not statistically different between the 2.5 and $5.0 \mathrm{~g}$ doses. However, inclusion of $7.5 \mathrm{~g}$ portions of any of the algae tested significantly increased $\mathrm{Fe}$ absorption compared with 2.5 or $5.0 \mathrm{~g}$ portions.

When calculated as doses of Fe absorbed from the maizebread meals, based on the mean Fe content of each meal and their percentage of absorption, the amount of Fe absorbed was $0.13,0.14$ and $0.24 \mathrm{mg}$ from Porphyra sp., 0.13, 0.20 and $0.45 \mathrm{mg}$ from Ulva sp. and $0.30,0.45$ and $1.23 \mathrm{mg}$ from Sargassum sp. for maize breads prepared with $2 \cdot 5,5 \cdot 0$ and $7 \cdot 5 \mathrm{~g}$ algae/maize bread, respectively.

Fe absorption from the same algae, but administered with wheat bread, is shown in Table 4 . The inclusion of the three algae studied, in any of the concentrations tested, significantly increased $\mathrm{Fe}$ absorption compared with the bread without algae addition. As observed with maize bread, the use of 2.5 or $5.0 \mathrm{~g}$ doses was not statistically different in terms of absorption. However, adding $7.5 \mathrm{~g}$ of any of the three algae (Ulva sp., Sargassum sp. or Porphyra sp.), significantly improved Fe absorption compared with the other two doses tested, except for the $5.0 \mathrm{~g}$ dose of Sargassum sp., in which absorption was no different from the bread containing $7.5 \mathrm{~g}$ of the same algae.

Experiments with wheat bread showed a similar percentage of absorption between the three algae tested, comparing the same doses. This is different from results obtained with rice $^{(24)}$ and maize bread, where absorptions, although without statistical significance, were higher for Porphyra sp. and Sargassum sp. and lower for Ulva sp.

When expressed as total dose of $\mathrm{Fe}$ absorbed from the wheat-bread meals containing algae, the $\mathrm{Fe}$ supplied was $0.21,0.22$ and $0.35 \mathrm{mg}$ from Porphyra sp., 0.34, 0.35 and $0.76 \mathrm{mg}$ from Ulva sp., and 0.39, 0.88 and $1.54 \mathrm{mg}$ from Sargassum sp. It can be noticed that although the highest percentage of Fe absorption was achieved with Ulva sp., the highest $\mathrm{Fe}$ intake was obtained with Sargassum sp., due to its $\mathrm{Fe}$ content.

\section{Discussion}

Porphyra is one of the most consumed algae in Japan ${ }^{(1)}$, while Ulva and Sargassum are widely consumed in Hawaii ${ }^{(25)}$. In Western countries algae consumption has been increasing for quite some time now. France uses at least ten species as food and condiments ${ }^{(26)}$. In Mexico, Eucheuma isiforme is used as emulsifier in a local beverage called 'atole'. In Chile the consumption of Durvillea antártica (cochanyuyo), Gracilariopsis and Ulva lactuca, fresh, cooked or canned, is common, while Ulva fasciata, Sargassum polyceratium, Sargassum partans and Turbinaria turbinata are common in Cuba. The most consumed algae in the Cariribbean is Gracilariopsis sp., especially as a refreshing drink know as 'sea moss drink' ${ }^{27,28)}$.

Table 2. Anthropometrical and haematological characteristics of subjects participating in iron absorption studies from preparations of algae with maize or wheat

(Mean values and standard deviations)

\begin{tabular}{|c|c|c|c|c|c|c|c|c|c|c|c|c|}
\hline & \multicolumn{2}{|c|}{ Study $1(n 16)$} & \multicolumn{2}{|c|}{ Study 2 ( $n 15)$} & \multicolumn{2}{|c|}{ Study 3 ( $n 15)$} & \multicolumn{2}{|c|}{ Study 4 ( $n 11)$} & \multicolumn{2}{|c|}{ Study 5 (n 14) } & \multicolumn{2}{|c|}{ Study 6 ( $n 12)$} \\
\hline & Mean & SD & Mean & SD & Mean & SD & Mean & SD & Mean & SD & Mean & SD \\
\hline \multicolumn{13}{|l|}{$\operatorname{Sex}(n)$} \\
\hline Female & \multirow{2}{*}{\multicolumn{2}{|c|}{$\begin{array}{c}11 \\
5\end{array}$}} & \multirow{2}{*}{\multicolumn{2}{|c|}{$\begin{array}{c}13 \\
2\end{array}$}} & \multicolumn{2}{|c|}{13} & \multicolumn{2}{|c|}{7} & \multirow{2}{*}{\multicolumn{2}{|c|}{$\begin{array}{c}10 \\
4\end{array}$}} & \multicolumn{2}{|c|}{8} \\
\hline Male & & & & & \multicolumn{2}{|c|}{2} & \multicolumn{2}{|c|}{4} & & & \multicolumn{2}{|c|}{4} \\
\hline Age (years) & 35.9 & 14.9 & 38.7 & $17 \cdot 7$ & 31.6 & $12 \cdot 7$ & 38.4 & $11 \cdot 1$ & 32.6 & $18 \cdot 1$ & $40 \cdot 2$ & 20.1 \\
\hline Weight (kg) & 64.7 & $11 \cdot 3$ & $68 \cdot 1$ & $12 \cdot 9$ & 60.9 & $9 \cdot 4$ & 60.5 & $10 \cdot 0$ & 64.1 & $16 \cdot 6$ & 71.3 & $15 \cdot 5$ \\
\hline Height $(\mathrm{cm})$ & 155 & 0.08 & 166 & 0.06 & 161 & 0.06 & 165 & 0.04 & 154 & 0.09 & 166 & 0.11 \\
\hline $\mathrm{Hb}(\mathrm{g} / \mathrm{l})$ & 132 & 14 & 132 & 8 & 125 & 14 & 124 & 14 & 128 & 12 & 131 & 14 \\
\hline Packed cell volume (\%) & 41 & 3 & 43 & 2 & 41 & 4 & 42 & 4 & 44 & 4 & 43 & 4 \\
\hline Serum Fe $(\mu \mathrm{g} / \mathrm{l})$ & 930 & 410 & 1030 & 310 & 1020 & 480 & 1140 & 430 & 1000 & 320 & 1090 & 210 \\
\hline UIBC $(\mu \mathrm{g} / \mathrm{l})$ & 2200 & 700 & 2350 & 600 & 2170 & 670 & 2650 & 720 & 2320 & 620 & 2200 & 600 \\
\hline TIBC $(\mu \mathrm{g} / \mathrm{l})$ & 3130 & 470 & 3380 & 530 & 3190 & 380 & 3790 & 440 & 3310 & 620 & 3300 & 640 \\
\hline Transferrin saturation (\%) & 31 & 15 & 31 & 9 & 33 & 17 & 31 & 12 & 31 & 9 & 35 & 8 \\
\hline Ferritin (ng/ml) & 29 & 3 & 32 & 2 & 26 & 3 & 26 & 3 & 26 & 2 & 40 & 2 \\
\hline
\end{tabular}

UIBC, unsaturated Fe-binding capacity; TIBC, total Fe-binding capacity. 
Table 3. Iron absorption in human subjects from maize-based diets containing three concentrations of different species of marine algae (Ulva sp., Sargassum sp. and Porphyra sp.)

(Mean values and standard deviations)

\begin{tabular}{|c|c|c|c|c|c|c|}
\hline & \multicolumn{6}{|c|}{ Fe absorption (\%) } \\
\hline & \multicolumn{2}{|c|}{$\begin{array}{l}\text { Study } 1 \text { Ulva sp. } \\
\qquad(n \text { 16) }\end{array}$} & \multicolumn{2}{|c|}{$\begin{array}{c}\text { Study } 2 \\
\text { Sargassum sp. } \\
(n 15)\end{array}$} & \multicolumn{2}{|c|}{$\begin{array}{l}\text { Study } 3 \\
\text { Porphyra sp. } \\
(n 15)\end{array}$} \\
\hline & Mean & SD & Mean & SD & Mean & SD \\
\hline \multicolumn{7}{|l|}{$\operatorname{Sex}(n)$} \\
\hline Female & \multirow{2}{*}{\multicolumn{2}{|c|}{$\begin{array}{c}11 \\
5\end{array}$}} & \multicolumn{2}{|c|}{13} & \multicolumn{2}{|c|}{13} \\
\hline Male & & 5 & \multicolumn{2}{|c|}{2} & \multicolumn{2}{|c|}{2} \\
\hline Maize meal & $2 \cdot 7^{\mathrm{a}}$ & 1.4 & $3 \cdot 0^{\mathrm{a}}$ & $1 \cdot 8$ & $2 \cdot 6^{\mathrm{a}}$ & $1 \cdot 3$ \\
\hline Maize meal $+2.5 \mathrm{~g}$ algae & $8 \cdot 7^{b}$ & 1.7 & $11 \cdot 2^{b}$ & $1 \cdot 7$ & $12 \cdot 8^{\mathrm{b}}$ & 1.6 \\
\hline Maize meal $+5.0 \mathrm{~g}$ algae & $9 \cdot 5^{b}$ & 1.6 & $9 \cdot 8^{b}$ & 1.6 & $12 \cdot 4^{\mathrm{b}}$ & 1.5 \\
\hline Maize meal $+7.5 \mathrm{~g}$ algae & $16 \cdot 6^{c}$ & $2 \cdot 2$ & $19 \cdot 0^{c}$ & $1 \cdot 7$ & $19 \cdot 4^{c}$ & $2 \cdot 2$ \\
\hline
\end{tabular}

${ }^{a, b, c}$ Mean values within a column with unlike superscript letters were significantly different $(P<0.05)$.

On the other hand, algae overpopulation constitutes a serious problem in many regions of the world, but it is particularly severe in tropical regions were sun radiation and water temperature favour algae growth. The problem becomes more serious since these algae suffocate complete water bodies, becoming inactive due to the impossibility of light penetration and $\mathrm{O}_{2}$ depletion. There is not an economically feasible and simple way to control algae overgrowth in an environmentally friendly fashion. There are many reports and evidence about the excellent nutritional value of algae; therefore an alternative to control the massive growth in tropical regions could be their use as a source of nutrients for human or animal consumption.

It has been reported that some algae species contain important amounts of $\mathrm{Fe}$, especially green algae such as the Ulva species that grow uncontrollably in some Caribbean coasts and are considered as waste for habitants of those regions ${ }^{(29)}$. The chemical form of $\mathrm{Fe}$ contained in different algae has not been described, at least for the three species included in the present study. There are some interesting studies on $\mathrm{Fe}$ requirements in different soils, with organic and inorganic forms of added $\mathrm{Fe}$, and like with earth vegetables, $\mathrm{Fe}$ content in algae varies according to geographical location and the time of year ${ }^{(24)}$.
The three species tested in the present study showed a high Fe content, especially Sargassum sp. with 157 mg Fe/100 g dry weight. The present study also shows that this alga presented the highest content in polyphenols and antioxidant capacity, and as reported previously, also of ascorbic acid, reaching a concentration of $362.44 \mu \mathrm{g} / \mathrm{g}$ dry weight, compared with 37.8 in Ulva sp. and 232 in Porphyra ${ }^{(24)}$.

Fe absorption from maize bread was significantly increased by the inclusion of algae in the amounts and species used in the present study. Of the doses tested, $7 \cdot 5 \mathrm{~g}$ produced the highest Fe absorption, significantly different from the control bread but also from the breads prepared with 2.5 or $5.0 \mathrm{~g}$ of the same algae. The evaluation of the amount of $\mathrm{Fe}$ absorbed from each maize bread depending on the algae and the doses administered showed that Sargassum sp. not only increased the Fe content of the bread but also that the $7.5 \mathrm{~g}$ doses would cover daily $\mathrm{Fe}$ needs, achieving an absorption higher than $1 \mathrm{mg}$ Fe. The absorption from maize breads prepared with $7.5 \mathrm{~g}$ of Ulva sp. or Porphyra sp. provided approximately 0.5 and $0.25 \mathrm{mg} \mathrm{Fe}$ in one serving.

Regarding wheat breads, absorption patterns were similar to the results with maize breads, except that percentages of absorption were higher from wheat. Absorption increased significantly by the addition of any of the three algae tested, and

Table 4. Iron absorption in human subjects from wheat bread-based diets containing three concentrations of different species of marine algae (Ulva sp., Sargassum sp. and Porphyra sp.)

(Mean values and standard deviations)

\begin{tabular}{|c|c|c|c|c|c|c|}
\hline & \multicolumn{6}{|c|}{ Fe absorption (\%) } \\
\hline & \multicolumn{2}{|c|}{$\begin{array}{l}\text { Study } 4 \text { Ulva sp. } \\
\qquad(n 11)\end{array}$} & \multicolumn{2}{|c|}{$\begin{array}{c}\text { Study } 5 \\
\text { Sargassum sp. } \\
(n 14)\end{array}$} & \multicolumn{2}{|c|}{$\begin{array}{c}\text { Study } 6 \\
\text { Porphyra sp. } \\
\text { (n 12) }\end{array}$} \\
\hline & Mean & $\mathrm{SD}$ & Mean & $\mathrm{SD}$ & Mean & SD \\
\hline \multicolumn{7}{|l|}{$\operatorname{Sex}(n)$} \\
\hline Female & \multicolumn{2}{|c|}{7} & \multicolumn{2}{|c|}{10} & \multicolumn{2}{|c|}{8} \\
\hline Male & \multicolumn{2}{|c|}{4} & \multicolumn{2}{|c|}{4} & \multicolumn{2}{|c|}{4} \\
\hline Wheat bread & $4 \cdot 0^{\mathrm{a}}$ & $1 \cdot 6$ & $3 \cdot 8^{\mathrm{a}}$ & $1 \cdot 8$ & $5 \cdot 2^{\mathrm{a}}$ & 1.5 \\
\hline Wheat bread $+2.5 \mathrm{~g}$ algae & $18 \cdot 6^{b}$ & 1.4 & $12 \cdot 6^{\mathrm{b}}$ & $1 \cdot 2$ & $15 \cdot 9^{b}$ & 1.4 \\
\hline Wheat bread $+5.0 \mathrm{~g}$ algae & $14 \cdot 3^{b}$ & $1 \cdot 7$ & $17 \cdot 9^{\mathrm{b}, \mathrm{c}}$ & $1 \cdot 7$ & $15 \cdot 3^{b}$ & 1.8 \\
\hline Wheat bread $+7.5 \mathrm{~g}$ algae & $24 \cdot 6^{c}$ & $1 \cdot 3$ & $22 \cdot 6^{\mathrm{C}}$ & 1.4 & $21 \cdot 8^{\mathrm{C}}$ & 1.6 \\
\hline
\end{tabular}

${ }^{a, b, c}$ Mean values within a column with unlike superscript letters were significantly different $(P<0.05)$. 
differences were not statistically significant between algae species, for the same doses. When results were calculated as net amount of Fe absorbed, it was noticed that $7.5 \mathrm{~g}$ of Sargassum sp. or Ulva sp. included in a wheat bread will provide 1.5 and $0.8 \mathrm{mg} \mathrm{Fe}$, while, from a bread containing $7.5 \mathrm{~g}$ Porphyra sp., the Fe absorbed was approximately $0.4 \mathrm{mg}$. Trying to establish a relationship between algae consumption and anaemia, we analysed recent data on prevalence of anaemia provided by the WHO, in countries known by a high algae consumption $^{(30)}$. It was not possible to draw conclusions since some countries such as Chile, Japan and UK showed prevalences of about $8 \%$ in adult women, while for the same age and sex group, anaemia prevalence was about $20 \%$ in Peru and China, indicating that other factors in diet and living styles should be taken into account.

The antioxidant properties of marine algae have been investigated in recent years, by the identification and quantification of capacities and compounds such as polyphenols, Fe-reducing power and ascorbic acid content, among many others ${ }^{(31-33)}$. Cinnamic acid and phenolic compounds act additively and/ or synergistically with carotenoids, ascorbic acid and Se probably by dismutating superoxide radicals, inactivating hydroxyl groups and chelating $\mathrm{Fe}^{(3,34,35)}$. There are other hydroxyl radical-scavenging products, such as dimethylsulfoniopropionate and dimethylsulfide, that have been described in algae ${ }^{(36)}$. In the present study, Sargassum sp. presented the highest polyphenol and ascorbic acid content of the algae tested (data for ascorbic acid not shown), and also the highest ferric-reducing capacity. Besides their effect as antioxidants, polyphenols and ascorbic acid have opposite effects on Fe absorption, which under the experimental conditions used in the present study resulted in a highly bioavailable Fe. Of the three species studied, Sargassum sp. presented the highest concentrations of $\mathrm{Fe}$, polyphenols, antioxidant capacity and Fe bioavailability. The high net $\mathrm{Fe}$ absorption obtained from this alga was the result of a high availability but also of the high Fe content found in this alga. Ulva sp. and Porphyra sp. contained similar concentrations of polyphenols, antioxidant power and $\mathrm{Fe}$ absorption, but different Fe contents, which resulted in significant differences in doses of $\mathrm{Fe}$ absorbed.

The high polyphenol content found in Sargassum sp. could be partly responsible for the antioxidant power reported here, and apparently did not significantly affect $\mathrm{Fe}$ absorption, probably due to the high ascorbic acid content reported in this alga, which not only improves Fe absorption, but also further increases the antioxidant capacity.

The rapid growth of the population and poverty that affects many countries worldwide have produced important malnutrition problems which have increased the need and the search for new food alternatives. In Venezuela, for example, in spite of a rich and exuberant marine flora, there have been limited efforts for the study and use of this resource. The present study shows the possibility of including marine algae as staple foods or as food fortificants for Latin American populations, since the inclusion of $7.5 \mathrm{~g}$ of Sargassum sp., Ulva sp. or Porphyra sp., included in a maize or wheat bread, will cover between 50 to more than $100 \%$ of the daily needs for $\mathrm{Fe}$.

With the results shown in the present study and in a previous one using rice as a vehicle for algae consumption, it would be interesting to continue studies to develop an algae-containing product of massive consumption in a country or a complete region. This product would be delivered as a social programme, to increase Fe and ascorbic acid intakes and to combat $\mathrm{Fe}$ deficiency and anaemia.

\section{Acknowledgements}

The present study was partially supported by the Fondo Nacional para Ciencia y Tecnología (FONACIT project number 2000001345) and IVIC-Locti funding. Algae were supplied by Biotecmar CA, maize flour was donated by Alimentos Polar Comercial, PROMESA, Venezuela and wheat flour by Cargill de Venezuela. There are no conflicts of interest for the authors. M. N. G. C. did the experimental design, collection of data, analysis of data and writing the manuscript. A. C. P., I. L., J. R. and M. F. Q. did the sample processing, quantification and analysis. J. R. did the field work and sample acquisition.

\section{References}

1. Nisizawa K, Noda R, Kikuchi R \& Watanabe T (1987) The main seaweed foods in Japan. Proc Int Seaweed Symp 12, 5-29.

2. Marsham S, Graham S \& Tobin M (2007) Comparison of nutritive chemistry of a range of temperate seaweeds. Food Chem 100, $1331-1336$.

3. Kuda T, Tsunekawa M, Goto H \& Araki Y (2005) Antioxidant properties of four edible algae harvested in the Noto Peninsula Japan. J Food Comp Anal 18, 625-633.

4. Norziah M \& Ching C (2000) Nutritional composition of edible seaweed Gracilaria changgi. Food Chem 68, 69-76.

5. Sánchez-Machado D, López J \& Paseiro P (2002) Highperformance liquid chromatographic determination of $\alpha$-tocopherol in macroalgae. J Chromatogr A 976, 277-284.

6. Wong K \& Cheung P (2000) Nutritional evaluation of some subtropical red and green seaweeds. Part I - proximate composition, amino acids profiles and some physicochemical properties. Food Chem 71, 475-482.

7. Rúperez P (2002) Mineral content of edible marine seaweeds. Food Chem 79, 23-26.

8. Nagai T \& Yukimoto T (2003) Preparation and functional properties of beverages made from sea algae. Food Chem 81, 327-332.

9. Funahashi H, Imai T, Tanaka Y, et al. (1985) Seaweed prevents breast cancer? Jpn J Cancer Res 92, 483-487.

10. Yamamoto I \& Maruyama H (1985) Effect of dietary seaweed preparations on 1,2-dimethyldrazine-induced intestinal carcinogenesis in rats. Cancer Lett 26, 241-251.

11. Food and Agriculture Organization, World Health Organization (1988), Requirements of Vitamin A, Iron, Folate and Vitamin $B_{12}$, FAO Food and Nutrition Series, no 23.Rome: FAO.

12. World Health Organization (1993) Indicators and Strategies for Iron Deficiency and Anaemia Programs. Geneva: WHO.

13. International Nutritional Anemia Consultative Group (INACG) (1977) Guidelines for the Eradication of Iron Deficiency Anaemia. A Report of the International Nutritional Anaemia Consultative Group. Washington, DC: The Nutrition Foundation.

14. Singleton VL \& Rossi JA (1965) Colorimetry of total phenolics with phosphomolybdic-phosphotungstic acid reagent. Am J Enol Vitic 16, 144-158.

15. Benzie IFF \& Strain JJ (1996) The ferric reducing ability of plasma (FRAP) as a measure of 'antioxidant power': the FRAP assay. Anal Biochem 239, 70-76. 
16. Taylor $\mathrm{P}$, Martínez-Torres $\mathrm{C}$, Méndez-Castellano $\mathrm{H}$, et al. (1995) Iron bioavailability from diets consumed by different socioeconomic strata of the Venezuelan population. $J$ Nutr 125, 1860-1868.

17. Crosby W, Munn J \& Furth F (1954) Standardizing a method for clinical hemoglobinometry. $U S$ Armed Force Med $J$ 5, $693-703$.

18. Anonymous (1978) Recommendation for measurement of serum iron in human blood. Br J Haematol 38, 291-294.

19. Anonymous (1978) The measurement of total and saturated iron-binding capacity in serum. Br J Haematol 38, 281-290.

20. Flowers C, Kuizon M, Beard S, Skikne B, Covell A \& Cook J (1986) A serum ferritin assay for prevalence studies of iron deficiency. Am J Hematol 23, 141-151.

21. Dern J \& Hart W (1961) Studies with doubly labeled iron. I. Simultaneous liquid scintillation counting isotopes of ${ }^{55} \mathrm{Fe}$ and ${ }^{59} \mathrm{Fe}$ as ferrous perchlorate. J Lab Clin Med 57, $322-330$.

22. Dern J \& Hart W (1961) Studies with doubly labeled iron. II. Separation of iron from blood samples and preparation of ferrous perchlorate for liquid scintillation counting. J Lab Clin Med 57, 460-467.

23. Nadler S, Hidalgo J \& Bloch T (1962) The Tulane table of blood volume in normal men. Surgery 51, 224-232.

24. Garcia-Casal M, Pereira A, Leets I, Ramirez J \& Quiroga M (2007) High iron content and bioavailability in humans from four species of marine algae. J Nutr 137, 2691-2695.

25. Abbott I (1979) The uses of seaweed as food in Hawaii. Econ Bot 32, 409-412.

26. Mabeau S \& Fleurence J (1993) Seaweed in food products: biochemical and nutritional aspects. Trends Food Sci Tech 4, 103-107.
27. Smith A (1990) Annotated Bibliography of the Seaweeds Used for Food in the West Indies. OECS Fishery Report no. 3. Kingstown, St Vincent and the Grenadines: Organization of Eastern Caribbean States Fisheries Unit.

28. Smith A (1992) Farming edible seaweeds in the Caribbean. Appl Phycol Forum 9, 1-2.

29. Chapman VJ \& Chapman DJ (1980) Seaweeds and Their Uses, 3rd ed. New York: Chapman and Hall.

30. World Health Organization (2008) WHO Global InfoBase. www.who.int/infobase (accessed February 2008).

31. Jiménez-Escrig A, Jiménez-Jiménez I, Pulido R \& SauraCalixto F (2001) Antioxidant activity of fresh and processed edible seaweeds. J Sci Food Agric 81, 530-534.

32. Qi H, Zhang Q, Zhao T, Hu R, Zhang $\mathrm{K} \&$ Li Z (2006) In vitro antioxidant activity of acetylated and benzoylated derivatives of polysaccharide extracted from Ulva pertusa (Chlorophyta). Bioorg Med Chem Lett 16, 2441-2445.

33. Yuan Y \& Walsh N (2006) Antioxidant and antiproliferative activities of extracts from a variety of edible seaweeds. Food Chem Toxicol 44, 1144-1150.

34. Vidal A, Fallarero A, Silva E, De Oliveira S, De Lima A, Pavan R, Vuorela P \& Mancini-Filho J (2006) Composición química y actividad antioxidante del alga marina roja Bryothamnion triquetrum (S.G.Gemelin) Howe (Chemical composition and antioxidant activity of the red algae Bryothamnion triquetrum (S.G.Gemelin) Howe). Braz J Pharm Sci 42, 589-600.

35. Le Tutour B, Benslimane F, Gouleau M, Gouygou J, Saadan B \& Quemeneur F (1998) Antioxidant and prooxidant activities of the brown algae, Laminaria digitata, Himanthalia elongata, Fucus vesiculosus, Fucus serratus and Ascophyllum nodosum. J Appl Phycol 10, 121-129.

36. Sunda W, Kiebert D, Kene R \& Huntsman S (2002) An antioxidant function for DMSP and DMS in marine algae. Nature 418, 317. 